\title{
Development of liver pate technology using pea meal
}

\author{
N.I. Tsareva*, T. S. Bychkova, E.N. Artemova, V. A. Kozlova, and Y. V. Rogacheva
}

Oryol State University named after I.S. Turgenev, Oryol 302026, Russia

\begin{abstract}
The article provides justification for the use of pea meal in the technology of liver pate. The article presents the research results of emulsifying ability of pea meal in terms of its use in the pate technology. It was established, that dry thermal treatment and SHF thermal treatment of pea affect negatively its emulsifying ability. According to the data obtained, the hydrothermal method of pea meal processing before adding it to pate mass was chosen. The authors evaluate the fractional composition of emulsion of the model system liver: pea mass. On the basis of the data obtained, a pate producing technology employing pea meal has been developed. Rheological and organoleptic surveys of the produced specimens are conducted. It is proved that new types of pate surpass the control sample in a number of indicators: the content of animal fat is reduced, the share of vegetable protein, the content of cellulose, potassium, calcium and magnesium are increased.
\end{abstract}

\section{Introduction}

One of the most important tasks of the government policy in the sphere of healthy food is to develop technologies of qualitatively new foodstuffs with the directed change of the chemical composition, adapted to the requirements of an organism, using innovative technologies. This aspect fully applies to the production of meat products, including pate that occupies a considerable share in the total amount of culinary meat products.

One of the solutions is the development of technology of the pate combining meat products with other additives that allows producing high quality product enriched with substances, physiologically important for a human body.

Pate is a sustaining homogenized product with the primary meat content. The soft texture is reached by special ways of raw products processing and selection of food ingredients. A wide range of meat and meat-andcereal pate is produced in the world according to its type and quality. It varies from delicacies produced from very expensive ingredients, for example, bird liver, eggs, cognac, etc., to a mass production product containing pork and beef liver and by-products [1,2].

One of the perspective directions on the range increase and the quality improvement of meat products is the complex use of raw products of animal and vegetable origin. Special attention should be paid to the question of maximum use of local raw products of vegetable origin. Legume crops are of great interest because of a considerable mass fraction of proteins content, their balance and functional characteristics. Among the legume crops, pea is of particular interest. It belongs to local traditional raw products, affordable and is of high nutritional and biological value. [3, 4].
The aim of the research is to examine functional and technological characteristics of pea meal and the development of a new type of liver pate on its basis.

\section{Materials and methods}

The following raw products were considered as the objects of the research: pea meal, vegetable oil, pork animal fat, chicken liver, beef liver.

The methods characterizing the emulsification processes, organleptic, physical and chemical indicators, rheological characteristics were used in the research.

Emulsifying ability (EA) was determined by estimating the volume of emulsified oil in centrifugation. To fulfil this, $7 \mathrm{~g}$ of a product was suspended in $100 \mathrm{ml}$ of water, followed by adding $100 \mathrm{ml}$ of vegetable oil or animal fat. The mixture was homogenized for $5 \mathrm{~min}$ and centrifugated for $10 \mathrm{~min}$. Then the volume of emulsified oil was measured to the total oil volume, the measurement results were expressed as a percentage.

The emulsion quality of model systems was determined by centrifugation. To fullfill this, a centrifuge tube with an emulsion was placed in a centrifuge and centrifugated at a speed of $1500 \mathrm{rps}-1$ for 5 minutes. After that, the height of each layer was measured and compared with the original height of the emulsion.

The emulsion stability (ES) was determined at a temperature of $800 \mathrm{C}$ for $30 \mathrm{~min}$ and cooled with water at a temperature for $15 \mathrm{~min}$. The emulsions were centrifugated at a speed of $500 \mathrm{rps}-1$ for $5 \mathrm{~min}$ and the volume of the emulsified layer was determined $[5,6]$.

Organoleptic indicators were determined by the profile method. The essence of the profile method is that the complex concept of one of the organoleptic

Corresponding author" tsarevani@mail.ru 
properties (taste, flavour, texture, etc.) is presented in the form of a set of simple components that are evaluated by the examiners on the quality, intensity and order of manifestation.

To determine the rheological indicators of pate the method ST-2-02 for structuremeter was used based on determining the effort of loading on «Bloom» indenter when immersing it in the prepared sample of gelatin to a depth of $4 \mathrm{~mm}$ at a speed of (immersion) $1.0 \mathrm{~mm} / \mathrm{s}$ after the effort of touch $7 \mathrm{~g}$. The obtained maximum magnitude of a loading force in $\mathrm{g}$ is interpreted as "Bloom strength" of the gel ("Bloom" method).

\section{Results and discussion}

Meal was subjected to various temperature effects - SHF thermal treatment and dry thermal treatment, in order to decide whether to add it to the product and to develop the production technology. The analysis of the research results shows that pea meal has high emulsifying ability, in all the processing methods emulsifying ability exceeds $80 \%$.

Table 1. The effect of pea meal processing method on emulsifying properties

\begin{tabular}{|c|c|c|c|}
\hline Type of fat & $\begin{array}{c}\text { Unprocessed } \\
\text { meal }\end{array}$ & $\begin{array}{c}\text { SHF thermal } \\
\text { treatment }\end{array}$ & $\begin{array}{c}\text { Dry thermal } \\
\text { treat-ment }\end{array}$ \\
\cline { 2 - 4 } & \multicolumn{3}{|c|}{ Emulsifying ability, \% } \\
\hline $\begin{array}{c}\text { Vegetable } \\
\text { oil }\end{array}$ & $99 \pm 0.5$ & $89 \pm 0.4$ & $84 \pm 0.7$ \\
\hline Animal fat & $92 \pm 0.5$ & $83 \pm 0.4$ & $81 \pm 0.6$ \\
\hline & \multicolumn{3}{|c|}{ Emulsion stability, \% } \\
\hline $\begin{array}{c}\text { Vegetable } \\
\text { oil }\end{array}$ & $95 \pm 0.5$ & $73 \pm 0.5$ & $68 \pm 0.6$ \\
\hline Animal fat & $86 \pm 0.3$ & $70 \pm 0.3$ & $65 \pm 0.4$ \\
\hline
\end{tabular}

It is noted that when vegetable oil is used as a base oil, unprocessed pea meal has the highest emulsifying ability, that is $99 \%$, that presupposes that almost all the amount of oil added is emulsified. After meal has been subjected to heat treatment emulsifying ability is reduced. It should be noted that animal fat is emulsified worse than vegetable oil, which is probably due to its structure. The emulsion stability as well as the emulsifying ability depends on the method of meal processing. And the higher the thermal effect, the worse the emulsion stability.

Thus, it was found that for preparation of pate and production of stable emulsion products, pea meal should not be precured. However, it is impractical to add meal in the dry state, meal is subjected to hydromechanical treatment in the process of cooking, therefore, the study of a model systems pea meal : water was of great interest.

Pea meal was cooked in water for 5 minutes with constant stirring, preventing the formation of lumps, the mass obtained was cooled to a temperature of $22-24{ }^{\circ} \mathrm{C}$ and was used to determine the emulsifying properties according to the standard procedure.

A system with a ratio of $1: 3$ possesses the best hydromodule, while the dry matter content is $33 \%$, which corresponds to the dry matter content in the raw product replaced by the formulation. The system with hydromodule 1:2, despite of the fact that it has high EA and ES, is very consistent, dry matter content is more than $50 \%$.

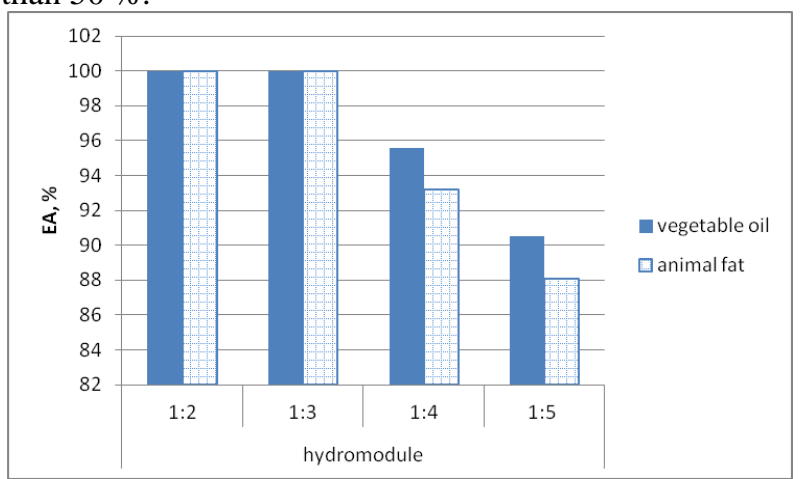

Fig. 1. The influence of a hydromodule on emulsifying ability of the model systems pea meal : water.

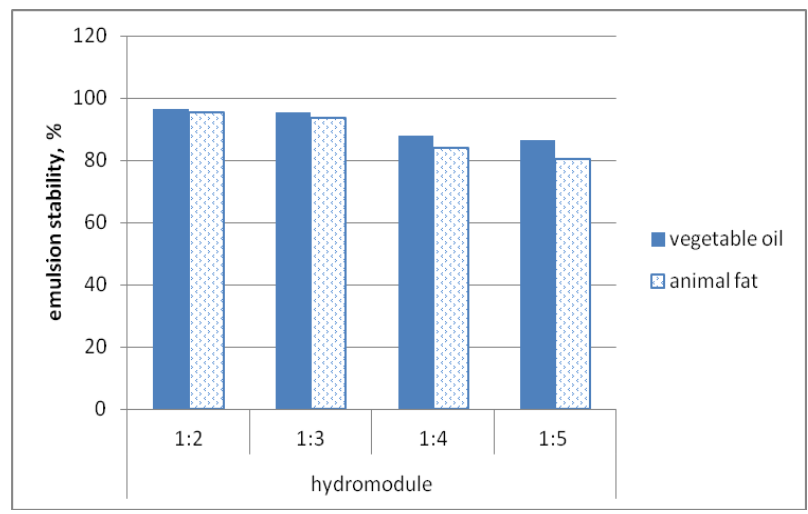

Fig. 2. The effect of a hydromodule on emulsion stability of the model systems pea meal : water.

As the formulation of a pate contains raw meat, the study of the emulsifying ability of the liver and pea meal mixture was of great interest. Pea meal is added in the form of mass boiled to a dry matter content of 33-35\%.

Model systems liver : pea mass were prepared by mixing the components with an interval of $10 \%$. Chicken and beef liver were used as meat raw products.

All the model systems were characterized by good emulsifying properties, the released oil on the surface of the tubes was not observed. Therefore, to estimate the quality of emulsions given, their fractional composition was evaluated [7-9].

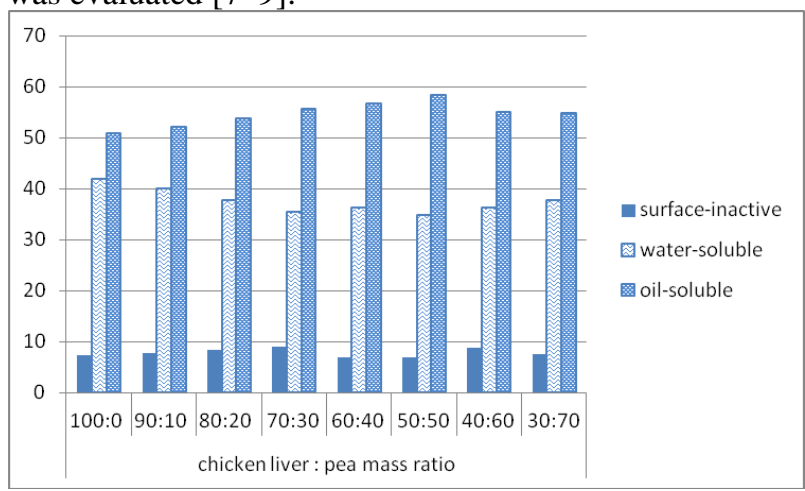

Fig. 3. The evaluation of fractional composition of emulsions with vegetable oil of model systems chicken liver : pea mass. 


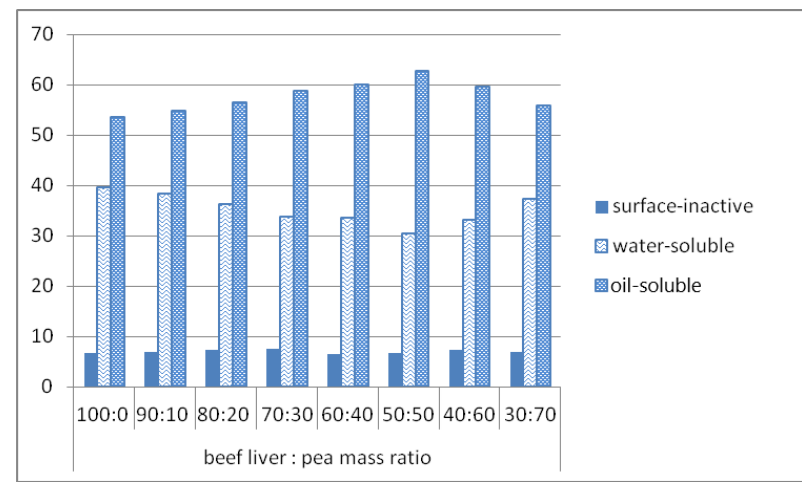

Fig. 4. The evaluation of fractional composition of emulsions with vegetable oil of model systems beef liver : pea mass.

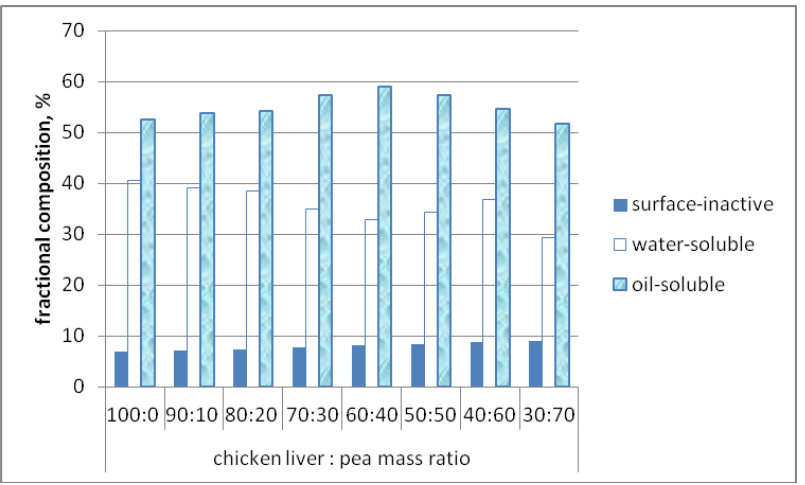

Fig. 5. The evaluation of fractional composition of emulsions with animal fat of model systems chicken liver : pea mass.

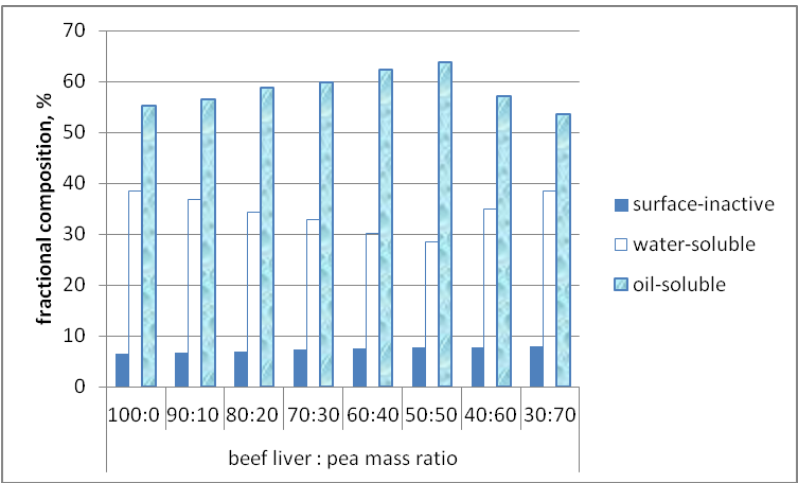

Fig. 6. The evaluation of fractional composition of emulsions with animal fat of model systems beef liver : pea mass.

According to the results of the studies, it was found that systems containing pea $40-50$ wt $\%$ for chicken liver and 40-60 wt \% for systems with beef liver were more stable.

For the development of a pate containing pea meal, the liver was replaced with pea meal in order to preserve the mass fraction of protein in it, to improve food product texture, reduce caloric content and to enrich with vegetable additives. When determining the rate of the meal added, the content of dry substances both in the liver and in the pea meal, which was used instead of the liver, was taken into account.

The rate of pea meal added was taken from the calculation of the preservation of the total amount of dry substances in the developed samples compared to the control sample.

On the basis of studies of emulsifying abilities of model systems liver : pea mass, the recipes of pate were developed with the replacement of liver with pea mass in the amount of 30 and $50 \%$.

The amount of meal for cooking pea mass was calculated on the basis that when boiling, the weight fraction of dry substances in the pea mass will be 34-37\%.

To cook the pate, pea meal is boiled in water to thick mass (dry substances content is $34-37 \%$ ) and is added at the stage of kneading of all the components according to the traditional technology of cooking pate from liver.

The results of organoleptic evaluation of pate from chicken liver show that the developed pate for all the indicators does not differ from the traditional pate, except for the indicator "taste", in the evaluation of which there is less bitterness of the native taste of liver.

Similar properties of this indicator are observed in pate from beef liver, the colour of samples with the addition of pea is lighter.

For a more complete study of the indicators "Texture" and "Taste and flavour", which are of priority for the consumer, the profile method of evaluation was used [10-12]. Diagrams of texture and taste and flavour evaluation are presented in figures 7-8.

\section{Texture of pate from chicken liver}
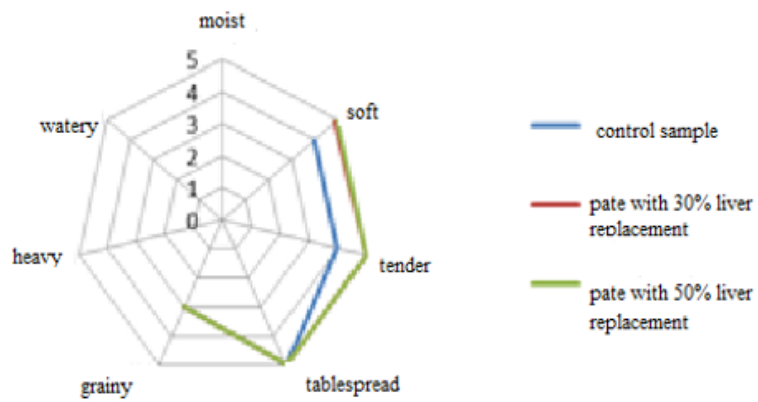

a)

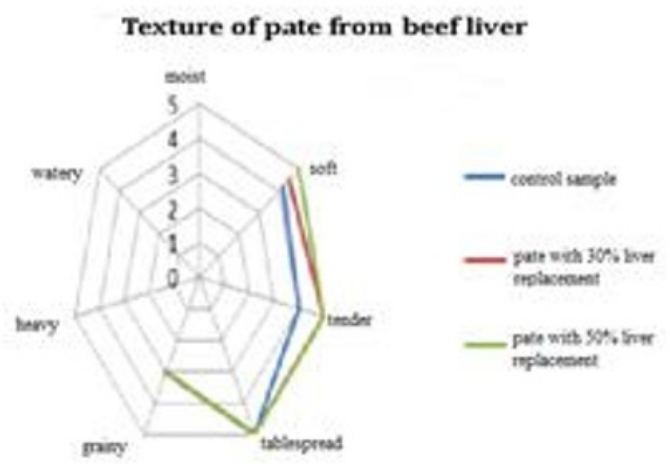

b)

Fig. 7. Profilograms of tasting evaluation of the pate texture: a) from chicken liver; b) from beef liver.

From assessment of profilograms of organoleptic evaluation, it can be noted that the developed pate produced from pea meal is not inferior, and in some respects superior of the control samples. 
Accordingly, it has a softer texture, does not have foreign off-flavours and flavours, including pea taste. It has a grainy texture thanks to including bulb onion and carrot in the formulation.

Taste and flavour of pate from chicken liver
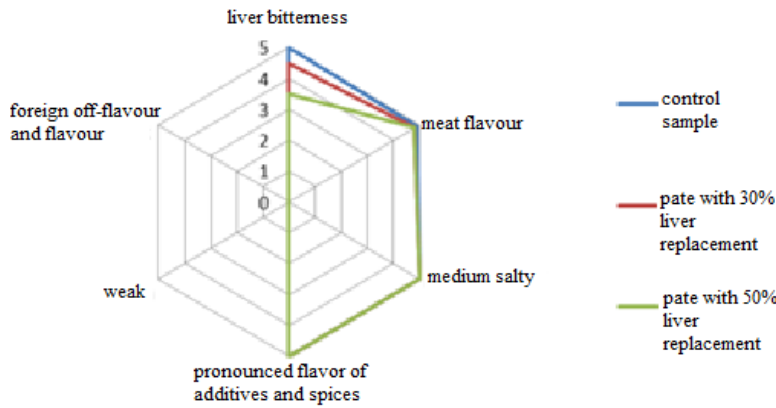

a)

Taste and flavour of pate from beef liver
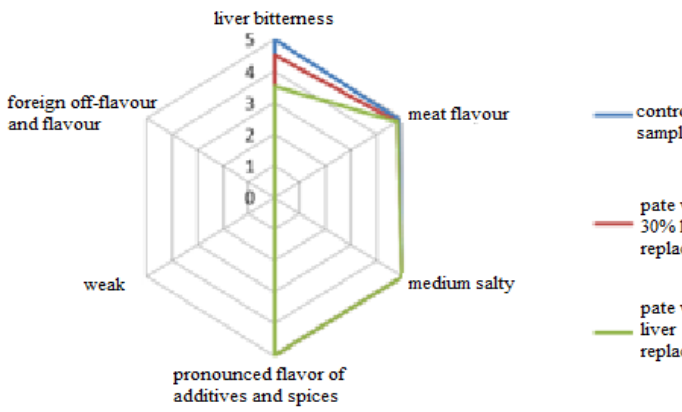

sample

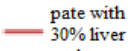

$30 \%$ liver

pate with $50 \%$ liver replacement

b)

Fig. 8. Profilograms of tasting evaluation of the pate taste: a) from chicken liver; b) from beef liver.

During the organoleptic evaluation, the tasters noted an improvement of the tablespread of the pate experimental samples in comparison with the control sample. The developed pate due to the addition of pea meal have a less pronounced bitter taste of the liver. Moreover, pate produced from chicken liver has a more soft texture compared to pate from beef liver, and in terms of "Taste and flavour", on the contrary, pate from beef liver is superior to the chicken one due to the properties of the liver itself.

For all other indicators (appearance, section view) the experimental samples have equivalent values.

The analysis of the rheological evaluation results of chicken liver pate showed that with the increase of exposure time on the product, the deformation increases in direct proportion to the time for all types of pate, while the deformation rate is directly proportional to the time of immersion.

However, the loading force is different for the control sample and for the pate with pea meal. Thus, when the indenter is immersed to a depth of $4 \mathrm{~mm}$, this indicator is $111.8,60.0$ and $56.5 \mathrm{~g}$ for the control samle and for samples with replacement of 30 and $50 \%$, respectively. This indicator decreases with the increase in the mass fraction of meal in pate, which indicates a softer texture and increased tenderness of pate with pea meal in comparison with the control sample.
When analyzing the measurement results of rheological properties of pate from beef liver using the device called "structuremeter", one can note the same patterns as in the study of rheological properties of pate produced from the chicken liver. Namely, the deformation increases with increasing time of exposure of the indenter on the product, and the smaller the loading force, the greater the deformation and the time of immersion. For example, at a deformation of $4 \mathrm{~mm}$ the loading force is $125.3,92.4$ and $75.6 \mathrm{~g}$.

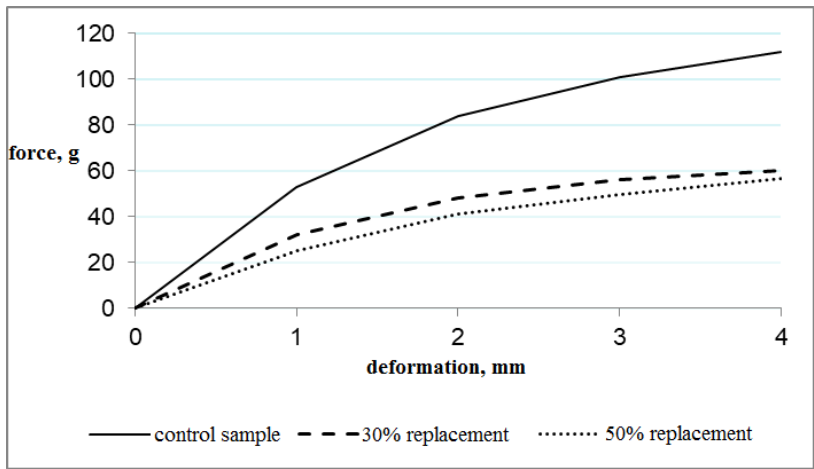

Fig. 9. The change of loading force on the indenter depending on the depth of penetration into chicken liver pate.

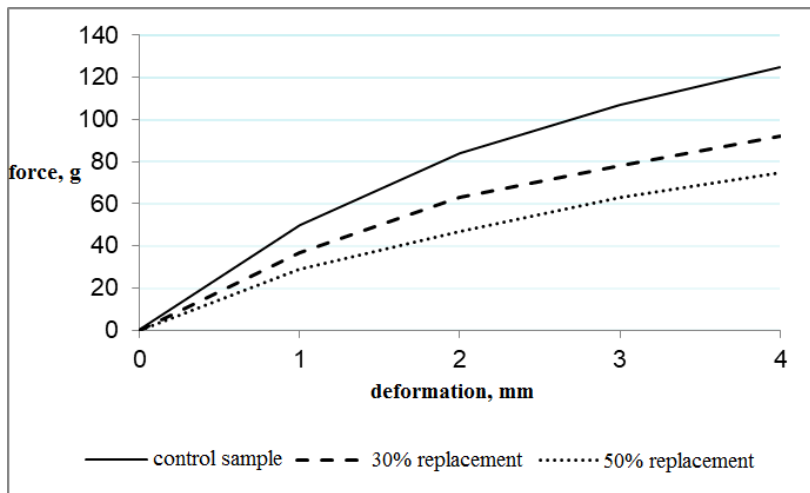

Fig. 10. The change of loading force on the indenter depending on the depth of penetration into beef liver pate.

Accordingly, the developed pate with pea meal has a softer texture than the traditional one, whereas chicken liver pate has a less heavy texture than beef liver one [13-17].

The analysis of the results of nuitrition and energy value showed that in many respects the developed pate with pea meal is not inferior, and in some cases, surpasses the control samples.

There is a decrease in the fat content in all the samples - by $19 \%$ with $30 \%$ replacement and by $32 \%$ for pate with pea meal, the content of which is $50 \%$.

The fiber content increases 8.8 times for all the types of pate with pea content of $30 \%$, and 14.4 times for all the types of pate when replacing the liver by $50 \%$.

There is an increase in the content of potassium, calcium and magnesium.

Replacing the liver with pea meal allows reducing the content of animal protein in the final product and increasing the content of vegetable protein, the deficiency of which is a frequent phemomenon. 
Samples with liver replacement of $30 \%$, both for chicken and beef pate show the best quality indicators.

\section{Conclusion}

Theoretical and experimental justification of the use of pea meal in the production of pate allowed establishing the following:

- pea meal has high emulsifying properties;

- the best way to add pea meal in pate is by introducing pea mass substituting $30 \%$ of the mass fraction of the liver.

Therefore, the use of pea meal in the liver pate technology allowed us to improve nutrition value, organoleptic properties and rheological characteristics of the final product.

\section{References}

1. B.A. Bazhenova, S.K. Balzhinimaeva, Equipment and technol. of food product. 4, 19-23 (2011)

2. G.V. Gurinovich, M.A. Subbotina, Meat industry 7, 36-40 (2013)

3. N.I. Tsareva, Legumes in the technology of food products with aerated texture (State UniversityESPC Publishing, Oryol, 2014)

4. E.A. Novitskaya, N.B. Glebova, N.I. Tsareva, Vegetable raw materials as a stabilizer for food products (State University-ESPC, Oryol, 2013)

5. S.S. Ahlawat, D.P. Sharma, N. Khanna, R.S. Dabur, Development of low fat emulsion based smoked sausages using different humectants Asian J. Of Dairy and Food Res. 31, 306-310 (2012)
6. A.S. Adheeb Usaid, J. Premkumar, T.V. Ranganathan, Emulsion and its applications in Food Processing - A Review Int. J. of Engineer. Res. and Applicat. 4(4) (Version 1), 241-248 (April 2014)

7. Y. E. Ladjal, M. Chibane, Int. Food Res. J. 22(3), 987-996 (2015)

8. S.A. Wani, P. Kumar, J. of Food Research and Technol. 2(3), 124-129 (2014)

9. L.F. Polesi, S.B.S. Sarmento, C.B. Prudente dos Anjos, Braz. J. Food Technol., Campinas 14(1), 74-81 (2011)

10. L. Steen, I. Fraeye, E. De Mey, O. Goemaere, H. Paelinck, I. Foubert, Food and Bioprocess Technol. 7(2), 496-505 (2014)

11. O.P. Singh, J.N. Singh, M.K. Bharti, Kumari Sony, J. of Food Sci. and Technol. - Mysore 45(5), 460-462 (2008)

12. A.K. Verma, R. Banerjee, J. Food Sci. Technol. 47(3), 247-257 (2010)

13. K. Kaack, H.N. Lærke, A.S. Meyer, Eur. food res. technol. 233(2), 267-272 (2006)

14. Nitin Mehta, S.S. Ahlawat, D.P. Sharma, R.S. Dabur, J. of Food Sci. and Technol. - Mysore 52(2), 633-647 (2015)

15. E. Okuskhanova, B. Assenova, M. Rebezov, Z. Yessimbekov, Pak. J. Nutr. 15(3), 217-222 (2016)

16. M.P. Piñero, K.Q. Parra, Y. Barboza, E. Arévalo, Revista de la Facultad de Agronomia 31, 678-687 (2014)

17. A.M. Martín-Sánchez, G. Ciro-Gómez, J. VilellaEsplá, J.Á. Pérez-Álvarez, E. Sayas-Barberá, Foods 6(11), 94 (2017) 